\title{
E o diafragma?
}

\section{What about the diaphragm?}

\author{
ROBERTO SAAD JUNIOR
}

E bem conhecido que os ferimentos na região de transição tóraco-abdominal são potencialmente causadores de ferimentos diafragmáticos. Segundo a nossa experiência, 30\% destes ferimentos atingem o diafragma. Na literatura encontramos uma incidência entre 20 e 48\% ${ }^{1,2}$.

Das lesões diafragmaticas, 70\% delas apresentam sintomatologia abundante, de modo que o cirurgião no serviço de emergência não terá nenhuma dificuldade em estabelecer o este diagnóstico tratá-las convenientemente. Porém, 30\% delas são oligossintomáticas ou mesmo assintomáticas. São as lesões diafragmáticas isoladas ou as acompanhadas de lesões viscerais intra-abdominais que, em um primeiro momento, ainda não apresentaram sintomas. Estas, com o exame clínico realizado durante a evolução e observação do doente, aparecem e daí indicamos a laparotomia e, portanto, o diagnóstico da lesão diafragmática. Em 8 a 10\% destes doentes as lesões diafragmáticas são isoladas 3 e, nestes casos, não há como fazer o diagnóstico de modo convencional. Para tanto, é necessária a realização da toracoscopia ou laparoscopia de rotina para a confirmação diagnóstica ${ }^{4}$.

Vem a primeira pergunta: vale a pena a realização deste exame invasivo para surpreender 10\% de ferimentos diafragmáticos isolados para em seguida promover a sua sutura? Claro que sim, pois deixar uma ferida no diafragma é dar uma chance ao doente de desenvolver precocemente ou em um futuro distante uma hérnia diafragmática com todas as suas conhecidas consequências. Insistir no diagnóstico mesmo com exames invasivos é até o momento, em nossa opinião, a orientação ideal.

Segunda pergunta: se a lesão diafragmática não for diagnosticada, existe alguma possibilidade deste músculo cicatrizar espontaneamente?

Para responder a tal pergunta realizamos uma séria de trabalhos experimentais, desde o ano de 2001, quando pudemos verificar que: $91,1 \%$ das lesões de $5 \%$ da superfície do diafragma cicatrizaram sendo 100\% à direita e $83 \%$ à esquerda5; lesões de $30 \%$ da superfície do diafragma do lado esquerdo cicatrizaram espontaneamente em 12,5\% ; a análise da evolução natural de ferimentos penetrantes, com extensão de 30\%, no diafragma, no lado direito, durante 21 dias em 28 ratos, evidenciou a ocorrência de cicatrização espontânea em 54\% das lesões ${ }^{7}$.

De modo que, após a realização destes estudos, confirmando a possibilidade de cicatrização espontânea do diafragma, surgiu a terceira pergunta: podemos realizar um tratamento não operatório em ferimentos da zona de transição tóraco-abdominal em doentes assintomáticos mesmo que possivelmente sejam portadores de lesões diafragmáticas?

Vamos analisar este aspecto comparando com o que realizamos hoje em tratamento não operatório de lesões de vísceras parenquimatosas: rim, baço e fígado.

Nestes casos existem postulados que devem ser seguidos. Nestas situações, optando-se por este tratamento, faz-se mister: realizar o diagnóstico da lesão; ter condições de caracterizar estas lesões: gravidade, tamanho, etc.; ter condições de acompanhar a evolução destas lesões; estabelecer o tempo de acompanhamento; alta definitiva.

Isto se consegue por meio de exames de imagens disponíveis. Sabemos que, caso o hospital não ofereça infraestrutura suficiente, não será possível a realização de um tratamento não operatório para estes doentes portadores de lesões das vísceras citadas.

Voltemos aos ferimentos diafragmáticos. Para estes casos ainda não existem métodos que possam nos fornecer o diagnóstico com segurança, portanto o primeiro postulado não pode ser cumprido. Se não temos o diagnóstico, não temos como caracterizar a possível lesão. Não temos também meios de acompanhar o ferimento, isto é, se está ocorrendo melhora ou não, muito menos estabelecer o tempo de acompanhamento.

Pois bem, quarta pergunta: como podemos indicar um tratamento não operatório em doentes com suspeita de ferimentos diafragmáticos à direita se não temos certeza, nem mesmo se existe, este ferimento e, se existe, qual seria a sua evolução?

Para esta pergunta acredito que caibam duas respostas: a) apesar da existência de hérnia diafragmática à direita ser um evento raro e, ainda mais, considerando que a possibilidade de cicatrização espontânea do músculo existe, mesmo assim, nós recomendamos que se realize o diagnóstico e o seu tratamento pelo menos até encontrarmos exames menos invasivos (imagem) que possibilitem o tratamento clínico; b) outra possibilidade é a de promover o tratamento não operatório para estes doentes, mesmo sem o diagnóstico da lesão. Neste caso, é imperi-

Professor Titular da Disciplina de Cirurgia Torácica. Livre Docente do Departamento de Cirurgia da Faculdade de Ciências Médicas da Santa Casa de São Paulo. Ex-Presidente do Colégio Brasileiro de Cirurgiões (gestões 2000-01; 2004-05). Presidente da Sociedade Brasileira de Cirurgia Torácica. 
oso assumir a responsabilidade de acompanhar este doente e alertá-lo de que, para qualquer sintoma que apareça, são necessários cuidados médicos, isto é, o cirurgião deve ter em mente que uma hérnia poderá aparecer no futuro e, por isso mesmo, jamais "dar alta" definitiva para este doente ${ }^{8}$.

\section{REFERÊNCIAS}

1. Zantut LF, Ivatury RR, Smith RS, Kawahara NT, Porter JM, Fry WR, et al. Diagnostic and therapeutic laparoscopy and penetrating abdominal trauma: a multicenter experience. J Trauma. 1997;42(5):825-9; discussion 829-31.

2. Ivatury RR, Simon RJ, Sthal WM. A critical evaluation of laparoscopy in penetrating abdominal trauma. J Trauma. 1993;34(6):822-7. discussion 827-8.
3. Gianini JA. Ferimentos penetrantes tóraco-abdominais e de tórax e abdome. Análise da morbilidade e mortalidade pós-operatórias [dissertação]. São Paulo: Santa Casa de São Paulo, Faculdade de Ciências Médicas; 1996.

4. Von Bathen LC, Smaniotto B, Kondo W, Vasconcelos CN, Rangel M, Laux GL. Papel da laparoscopia no trauma abdominal penetrante. Rev Col Bras Cir. 2005;32(3):127-31.

5. Perlingeiro JA, Saad R Jr, Lancelotti CL, Rasslam S, Candelária PC, Soldá SC. Natural course of penetrating diaphragmatic injury: an experimental study in rats. Int Surg. 2007;92(1):1-9.

6. Gonçalves R. Análise da evolução natural das feridas perfurocortantes equivalentes a $30 \%$ do diafragma esquerdo. Estudo experimental em ratos [dissertação]. São Paulo: Santa Casa de São Paulo, Faculdade de Ciências Médicas; 2008.

7. Rivaben $\mathrm{JH}$. História natural do ferimento diafragmático extenso à direita: estudo experimental em ratos [dissertação]. São Paulo: Santa Casa de São Paulo, Faculdade de Ciências Médicas; 2011.

8. Renz BM, Feliciano DV. Gunshot wounds to the right thoracoabdomen: a prospective study of nonoperatiive management. J Trauma. 1994;37(5):737-44 